\title{
Effect of pleurodesis with negative pressure suction plus bleomycin on malignant pleural effusions; a clinical trial
}

\author{
Masoud Rahimian ${ }^{\mathbb{D}}$, Salar Khazani Fard ${ }^{*}{ }^{\mathbb{D}}$, Mohammad Samet ${ }^{\mathbb{D}}$, Fatemeh Aghaei Meybodi ${ }^{\mathbb{D}}$ \\ Department of Internal Medicine, Shahid Sadoughi University of Medical Sciences, Yazd, Iran
}

\section{*Correspondence to}

Salar Khazani Fard, Email:

Saliyazdmed@gmail.com,

,s.khazenifard@ssu.ac.ir

Received 17 February 2019 Accepted 23 June 2019 Published online 27 July 2019

Keywords: Bleomycin, Malignant pleural effusion, Pleurodesis, Chemotherapy

\begin{abstract}
Introduction: About $50 \%$ of patients with metastatic cancers suffer from malignant pleural effusion. The goals of treatment for these patients should be to relieve pain, restore normal function, reduce or eliminate hospitalization, and make efficient use of medical care resources.

Objectives: This study aimed to evaluate the effect of negative pressure suction on the success rate of pleurodesis with bleomycin on malignant pleural effusion.

Patients and Methods: This study was conducted as before-after interventional study, without randomization. For all patients, $1 \mathrm{mg} / \mathrm{kg}$ bleomycin diluted with $50 \mathrm{~mL}$ distilled water, was injected into the chest tube. After changing the position of the patient, the clamp was opened and the tube was connected to the central suction with two chest bottles. The negative pressure suction was $20 \mathrm{cmH} 2 \mathrm{O}$. Before intervention and four weeks after the intervention, a simple decubitus lateral chest X-ray was taken and the amount of malignant pleural effusion was assessed and compared with the amount of pleural effusion before the insertion of the chest tube. If the pleural effusion level was greater than $10 \mathrm{~mm}$ from the outer part of the chest, pleurodesis was considered unsuccessful

Results: The mean age of patients was $60.44 \pm 10.48$ years (32-79 years); of which 12 patients (48\%) were male. The most common cancer was lung cancer $(48 \%)$. The success rate of treatment with bleomycin accompanied by negative pressure suction was $80 \%$ without a significant relationship with age, gender and type of cancer. Additionally, the results showed the improvement of the respiratory status and the pain level after the pleurodesis. The only side effect after bleomycin injection was fever in $84 \%$ of patients.

Conclusion: Bleomycin treatment accompanied by negative pressure suction can improve malignant pleural effusion and this method is recommended for these patients.

Trial registration: This study was registered in Iranian Registry of Clinical Trials (identifier: IRCT20180813040779N1; https://en.irct.ir/trial/33304, local ethical code\#IR.SSU.MEDICINE.REC.1396.264).
\end{abstract}

Citation: Rahimian M, Khazani Fard S, Samet M, Aghaei Meybodi F. Effect of pleurodesis with negative pressure suction plus bleomycin on malignant pleural effusions; a clinical trial. Immunopathol Persa. 2019;5(2):e20. DOI:10.15171/ ipp. 2019.20

\section{Introduction}

The pleura is the serous membrane covering the lung parenchyma, mediastinum, ribs and diaphragm. It is divided into parietal and visceral pleura $(1,2)$. A fluid layer called pleural fluid, which normally exists between the parietal and visceral pleura acting as a lubricant. The volume of this fluid per $\mathrm{kg}$ of body weight is $0.1-1.2 \mathrm{~mL}$, which increasing and decreasing of the secretion or decrease in the rate of excretion results in pleural effusion (3).

Based on the results of biochemical tests, such as determining the volume of protein and $\mathrm{LDH}$, the pleural effusion is divided into exudate and transudate forms, so that metastatic cancer is the most common cause of pleural effusion $(4,5)$. About $50 \%$

\begin{abstract}
Key point
In a clinical trial [before-after interventional (quasiexperimental) study, without randomization, without blinding], to evaluate the effect of negative pressure suction on the success rate of pleurodesis with bleomycin on malignant pleural effusion on 25 patients with malignant pleural effusion, we found bleomycin treatment accompanied by negative pressure suction can improve malignant pleural effusion.
\end{abstract}

of patients with metastatic cancer develop malignant pleural effusion. Malignant pleural effusion may be treated by different ways, and one of the ways to treat pleural effusion is drainage of a large amount of fluid. However, many patients necessitate the re-insertion of thoracentesis and

\footnotetext{
Copyright (C) 2019 The Author(s); Published by Nickan Research Institute. This is an open-access article distributed under the terms of the Creative Commons Attribution License (http://creativecommons.org/licenses/by/4.0), which permits unrestricted use, distribution, and reproduction in any medium, provided the original work is properly cited.
} 
pleurodesis $(6,7)$. The purpose of treatment for these patients should be to relieve pain, restore normal function, reduce or eliminate hospitalization, and make efficient use of medical care resources $(8,9)$.

In several studies, various materials such as talc, bleomycin and povidone iodine were used to perform pleurodesis $(7,10)$. Considering the prevalence and significant impact of malignant pleural effusion on the life-style of patients with various malignancies, finding an appropriate treatment to relieve the symptoms of this disorder and providing an effective with low complication has especial importance. In some cases, it is desirable to use a negative pressure to facilitate lung expansion and apply a constant suction with a negative pressure of 15 to $20 \mathrm{cmH}_{2} \mathrm{O}(11)$.

\section{Objectives}

Due to the lack of a similar study using pleurodesis with negative pressure suction, this study was designed to investigate the effect of negative pressure suction on the success rate of pleurodesis with bleomycin on malignant pleural effusion.

\section{Patients and Methods}

\section{Study population}

This study was conducted as before-after interventional (quasi experimental) study (in Shahid Sadouhhi hospital, Yaz), without randomization and blinding. Considering $95 \%$ confidence level and taking $60 \%$ success rate of the pleurodesis the method with bleomycin alone in these patients was based on the study by Nikbakhsh et al (12) and considering the $20 \%$ error, the sample size was considered 25 (Figure 1).

\section{Study setting}

For all patients, $1 \mathrm{mg} / \mathrm{kg}$ bleomycin, diluted with $50 \mathrm{~mL}$

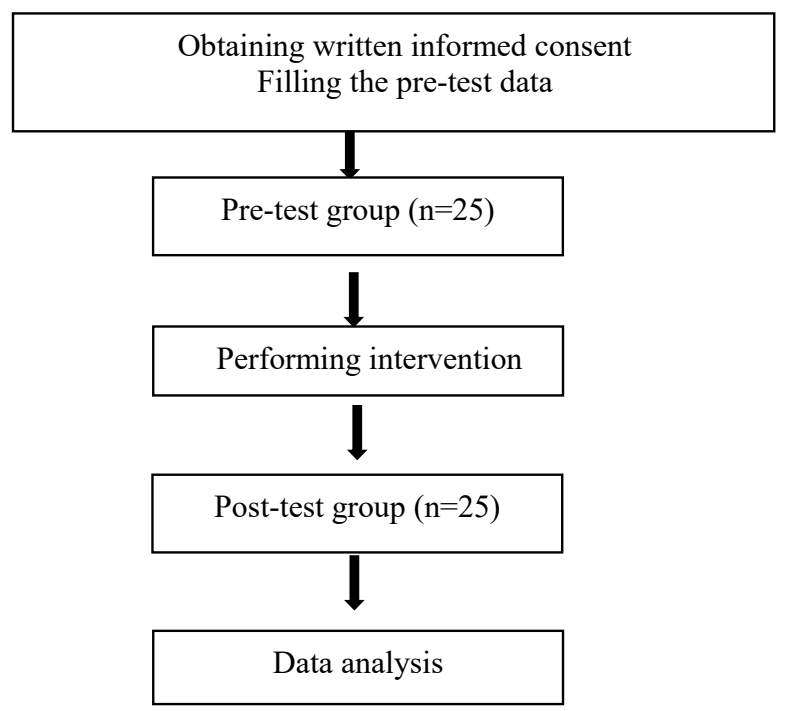

Figure 1. Flowchart of the study distilled water, was injected into the chest tube. After changing the position of the patient, the clamp was opened and the tube was connected to the central suction with two chest bottles. The negative pressure suction was $20 \mathrm{cmH}_{2} \mathrm{O}$.

Before intervention and 4 weeks after the intervention, a simple decubitus lateral chest X-ray was taken and the amount of malignant pleural effusion was assessed and compared with the amount of pleural effusion before the insertion of the chest tube.

If the pleural effusion level was greater than 10 $\mathrm{mm}$ from the outer part of the chest, pleurodesis was considered unsuccessful. Side effects such as pain, fever, dyspnea, during the intervention and four weeks after the intervention were evaluated.

\section{Inclusion criteria}

Inclusion criteria were cytological confirmed malignant pleural fluid, not having sensitivity to bleomycin, no history of previous chemotherapy with bleomycin.

\section{Exclusion criteria}

Exclusion criteria were patients aged less than 18 years and over 80 years, coagulation disorders (impaired coagulation profile, platelet count $<80000 / \mu \mathrm{L}$ ), previous history of pleurodesis, history of coagulation disorders and dissatisfaction of the patients.

\section{Ethical consideration}

The research followed the tenets of the Declaration of Helsinki. This study was approved by the ethics committee of Yazd University of Medical Sciences (\#IR. SSU.MEDICINE.REC.1396.264). Moreover, this study was registered in Iranian Registry of Clinical Trials (identifier: IRCT20180813040779N1; https://en.irct.ir/ trial/33304) and written informed consent was taken from all participants before any intervention. A complete explanation of the treatment method for patients was described and the patients were assured that their information would be confidential and would be used only for the purposes of the research. No additional costs were incurred by patients in the implementation of this study. This work has been conducted as part of internal medicine residential thesis of Salar Khazani Fard in Yazd University of Medical Sciences (\#5382).

\section{Statistical analysis}

The obtained data were entered into SPSS version 21 and analyzed with appropriate statistical methods including descriptive statistics (frequency indices and relative percentages) and inferential statistical tests. In all cases, a $P$ value of less than 0.05 was considered significant.

The present study was conducted as a clinical trial to evaluate the success rate of pleurodesis with negative pressure suction and bleomycin on 25 patients with malignant pleural effusion. The results of this study showed that the mean age of patients was $60.44 \pm 10.48$ 
years (32 to 79 years), of which 12 patients (48\%) were male and 13 patients (52\%) were female.

The results of treatment with negative pressure suction and bleomycin were successful in 20 patients and unsuccessful in 5 patients, the success rate of treatment with bleomycin with negative pressure suction in this study was $80 \%$. According to Table 1 , the most common cancer in patients was lung cancer (48\%). The success rate of treatment was $83.3 \%$ in men and $76.9 \%$ in women. According to the Chi-Square test, there was no significant difference between the success rate and gender of the patients $(P=0.682)$. According to Table 1 , which shows the success rate of treatment by the type of cancer, lung and breast cancer had a success rate of $75 \%$ since, in other cancers, the success rate was $100 \%$. Of course, the number of samples was low for other cancers except for lung and breast cancers. According to Table 2, the success rate of treatment in the patients less than 50 years of age was $66.7 \%$, while in the age group of $50-70$ years it was $83.3 \%$ and in the patients over 70 years of age, the success rate was $75 \%$. There was no significant relationship between the success rate of the treatment and the age group of the patients $(P=0.776)$.

According to Table 3, before the pleurodesis, $80 \%$ of patients had chest pain with pleuritic chest pain while

Table 1. Frequency distribution of the success rate of treatment with bleomycin by cancer

\begin{tabular}{llll}
\hline Type of cancer & Unsuccessful & Successful & Total \\
\hline Lung & $3(25)$ & $9(75)$ & $12(100)$ \\
Breast & $2(25)$ & $6(75)$ & $8(100)$ \\
Colon & $0(0)$ & $2(100)$ & $2(100)$ \\
Renal cell carcinoma & $0(0)$ & $1(100)$ & $1(100)$ \\
Stomach & $0(0)$ & $2(100)$ & $2(100)$ \\
Total & $5(20)$ & $2(80)$ & $25(100)$ \\
\hline
\end{tabular}

$P$ value: 0.812 .

Table 2. Frequency distribution of the success rate of treatment with bleomycin by age

\begin{tabular}{lccc}
\hline Age group & Unsuccessful & Successful & Total \\
\hline Less than 50 year & $1(33.3)$ & $2(66.7)$ & $3(100)$ \\
Between 50-70 years & $2(16.7)$ & $15(83.3)$ & $18(100)$ \\
More than 70 years & $1(25)$ & $3(75)$ & $4(100)$ \\
Total & $5(20)$ & $20(80)$ & $25(100)$ \\
\hline
\end{tabular}

$P$ value: 0.776 .

Table 3. Frequency distribution of the dyspnea and chest pain before and after pleurodesis

\begin{tabular}{lcc}
\hline Variable & $\begin{array}{c}\text { Before } \\
\text { pleurodesis }\end{array}$ & $\begin{array}{c}\text { After } \\
\text { pleurodesis }\end{array}$ \\
\hline Having chest pain & $20(80)$ & $5(20)$ \\
\hline Not having chest pain & $5(20)$ & $20(80)$ \\
Dyspnea with severe physical activity & $2(8)$ & $19(76)$ \\
Dyspnea with normal physical activity & $10(40)$ & $3(12)$ \\
Dyspnea with severe physical activity & $13(52)$ & $3(12)$ \\
\hline
\end{tabular}

only $20 \%$ of patients had chest pain after pleurodesis. This difference was tested using McNemar's test, which was significant $(P=0.001)$. Before pleurodesis, $8 \%$ of the patients with severe activity, $40 \%$ with normal activity, and $52 \%$ without activity had dyspnea. After pleurodesis, $76 \%$ with severe activity, $12 \%$ with normal activity, and $12 \%$ without activity had dyspnea showing improvement in the patient's respiratory status after pleurodesis. After bleomycin injection, $84 \%$ of patients had oral temperatures above $37.5^{\circ} \mathrm{C}$ and $16 \%$ had temperatures below $37.5^{\circ} \mathrm{C}$.

\section{Discussion}

Malignant pleural effusion is the secondary outcome of some malignancies such as lung and breast cancers, and lymphoma (13) More than 150000 people in the United States are currently suffering from malignant pleural effusion (14). The present study was conducted as a clinical trial to evaluate the success rate of pleurodesis with negative pressure suction and bleomycin in 25 patients with malignant pleural effusion.

In summary, the results of treatment with negative pressure suction and bleomycin in patients were successful in 20 patients and unsuccessful in five patients. The success rate of treatment with bleomycin accompanied by negative pressure suction in this study was $80 \%$. The success rate of treatment was $83.3 \%$ in men and $76.9 \%$ in women. However, there was no significant relationship between the success rate of treatment with gender, type of cancer and age, probably due to the low sample size.

The results of the present study showed that after pleurodesis, the chest pain was improved significantly in patients with pleural effusion, so that before pleurodesis, $80 \%$ of patients had pleuritic chest pain and after pleurodesis, only $20 \%$ of them had chest pain. Additionally, the respiratory status of the patients after pleurodesis was also improved. The only complication observed in this study was fever in $84 \%$ of patients.

A study by ONG et al, which compared status with talc and bleomycin on 36 patients with malignant pleural effusion, showed that the success rate for talc was $89 \%$ and for bleomycin was $70 \%$, but the success rate between the two groups was not significantly different. Complications including fever and chest pain were observed in both groups. Their study suggested that talc can be as effective as bleomycin in preventing the recurrence of malignant pleural effusion. One of the differences between the study of Ong et al and our study was the sample size and how to evaluate the success rate of the treatment, while Ong et al did not apply negative pressure suction (15).

In another study, which compared talc and bleomycin to treat malignant pleural effusion, it has been shown that both drugs are effective in reducing recurrence. In the study by Zimmer et al, success rate was determined as the absence of pleural effusion within 1.7 months of followup. They showed, the success rate in the bleomycin group was $79 \%$ and in the talc group was $90 \%$ (16). In another 
study by Noppen et al, the success rate in the bleomycin group was $75 \%$ while in the talc group was $78.6 \%$. In this study, treatment failure was repeated with pleural effusion with more than $50 \%$ primary fluid volume or the need for pleurodesis during the follow-up (17).

In addition to differences in the definition and evaluation of the success or failure rate of the treatment in these studies, none of them used negative pressure suction. A remarkable point in these two studies was the more effective treatment with talc. Although this difference was not statistically significant, more studies were needed to measure the difference. However, the result of the treatment of our study, which included bleomycin and negative pressure suction, was $80 \%$.

The results of the study by Nikbakhsh et al showed complete response to treatment in $66 \%$ of patients, partial response in $22 \%$ and treatment failure in $12 \%$ of patients. Thus, pleurodesis with bleomycin improved symptoms in nearly $88 \%$ of patients (12). One of the specificities of the present study was the time spent removing the thoracostomy tube, the duration of the patients' follow-up, the dose of bleomycin, and how to evaluate the success of the treatment. Similar to the study of Nikbakhsh et al, no significant relationship between response to treatment and type of tumor was seen, which was similar to the study conducted by Martinez et al. In the study of Martinez et al, after six months follow-up, $82 \%$ of the patients had complete response and $12 \%$ had partial response while in $6 \%$ of patients, treatment failure was observed (18). In other studies, the The success rate of treatment with bleomycin is different studies are satisfactory. In this regard, four studies reported its success rate from $62 \%$ to $81 \%(10,19-21)$.

Regarding complication, the majority of studies had not positive point except for fever and chest pain that was transient while in most studies, the most underlying conditions leading to malignant pleural effusion was lung and breast cancers, which is similar to the current study.

\section{Conclusion}

There was no significant correlation between success rate of treatment with gender, type of cancer and age. After pleurodesis, the level of chest pain was significantly improved while before the pleurodesis, $80 \%$ of patients had chest pain exacerbating by breathing (pleuritic chest pain) and after pleurodesis, only $20 \%$ had chest pain. In addition, the patients' respiratory status improved after the pleurodesis. Therefore, treatment with negative pressure suction accompanied by bleomycin, especially in regions where the thoracic surgeon is not present, can be used in patients with malignant pleural effusion.

\section{Limitations of the study}

Low sample size and not having control group were limitations of this study. The main limiting factors in comparing the success rate of treatment with sclerosis drugs used to treat malignant pleural effusion are the difference in selective criteria, the pleurodesis method and the criteria for assessing the success of treatment. Consequently, randomized controlled trials are necessary to examine the effects of these differences.

\section{Acknowledgments}

The authors of the paper express their sincere gratitude to deputy research of Yazd University of Medical Sciences and all patients who participated in this study

\section{Authors' contribution}

MR designed the experiment. MS and FAM supervised the project. FAM and SKF participated in collecting data. All authors discussed the results and commend on the final manuscript.

Conflicts of interest

The authors declare no conflict of interest.

\section{Ethical considerations}

Ethical issues (including plagiarism, double publication) have been completely observed by the authors. This article does not contain any studies with animals performed by any of the authors.

\section{Funding/Support}

This study was the result of a thesis of Yazd University of Medical Sciences (\#5382).

\section{References}

1. Roberts ME, Neville E, Berrisford RG, Antunes G, Ali NJ. Management of a malignant pleural effusion: British Thoracic Society pleural disease guideline 2010. Thorax. 2010;65:ii3240. doi: 10.1136/thx.2010.136994.

2. Davies C, Gleeson F, Davies R. BTS guidelines for the management of pleural infection. Thorax. 2003;58:ii18. doi: 10.1136/thorax.58.suppl_2.ii18

3. Porcel JM, Vives M. Etiology and pleural fluid characteristics of large and massive effusions. Chest. 2003;124:978-83. doi: 10.1378/chest.124.3.978.

4. Heffner JE, Highland K, Brown LK. A meta-analysis derivation of continuous likelihood ratios for diagnosing pleural fluid exudates. Am J Respir Crit Care Med. 2003;167:1591-9. doi: 10.1164/rccm.200301-048PP.

5. Ghelmani Y, Khazanifard S. Pleuritis in 25 year old Female with Systemic Lupus Erythromatosus: Case Report. IMMINV. 2019; 4. doi: 10.24200/imminv.v2i4.182.

6. Zarogoulidis K, Zarogoulidis P, Darwiche K, Tsakiridis K, Machairiotis N, Kougioumtzi I, et al. Malignant pleural effusion and algorithm management. J Thorac Dis. 2013;5:S413. doi: 10.3978/j.issn.2072-1439.2013.09.04.

7. 7.Korsic M, Badovinac S, Cucevic B, Janevski Z. Talc pleurodesis improves survival of patients with malignant pleural effusions: case-control study. Wien Klin Wochenschr. 2015;127:963-9. doi: 10.1007/s00508-015-0716-8.

8. Society AT. Management of malignant pleural effusions. Am J Respir Crit Care Med. 2000;162:1987-2001. doi: 10.1164/ ajrccm.162.5.ats8-00.

9. Antunes G, Neville E. Management of malignant pleural effusions. Thorax. 2000;55:981-3.

10. Ostrowski MJ. An assessment of the long-term results of controlling the reamlumulation of malignant effusions using intracavity bleomycin. Cancer. 1986;57:721-7.

11. Light RW. Pleural diseases. Lippincott Williams \& Wilkins; 
2007.

12. Nikbakhsh N, Amiri AP, Hoseinzadeh D. Bleomycin in the treatment of 50 cases with malignant pleural effusion. Caspian J Intern Med. 2011;2:274-8.

13. Schwartz S, Brunicardi F, Andersen D, Billiar T, Dunn D, Hunter J. Schwartz's principles of surgery. New York: McGrawHill Education; 2015.

14. Light R. Pleural effusions related to metastatic malignancies. Pleural diseases. 2001;4:121-4.

15. Ong KC, Indumathi V, Raghuram J, Ong YY. A comparative study of pleurodesis using talc slurry and bleomycin in the management of malignant pleural effusions. Respirology. 2000;5:99-103.

16. Zimmer PW, Hill M, Casey K, Harvey E, Low DE. Prospective randomized trial of talc slurry vs bleomycin in pleurodesis for symptomatic malignant pleural effusions. Chest. 1997;112:430-4. doi: 10.1378/chest.112.2.430.

17. Noppen M, Degreve J, Mignolet M, Vincken W. A prospective, randomised study comparing the efficacy of talc slurry and bleomycin in the treatment of malignant pleural effusions. Acta Clin Belg. 1997;52:258-62.

18. Martinez-Moragon E, Aparicio J, Rogado M, Sanchis J, Sanchis F, Gil-Suay V. Pleurodesis in malignant pleural effusions: a randomized study of tetracycline versus bleomycin. Euro Res J. 1997;10:2380-3.

19. Hamed H, Fentiman I, Chaudary M, Rubens R. Comparison of intracavitary bleomycin and talc for control of pleural effusions secondary to carcinoma of the breast. Br J Surg. 1989;76:12667. doi:10.1002/bjs.1800761214.

20. Mishra EK, Clive AO, Wills GH, Davies HE, Stanton AE, AlAloul $M$, et al.Randomized controlled trial of urokinase versus placebo for nondraining malignant pleural effusion. Am J Respir Crit Care Med. 2018;197:502-508. doi: 10.1164/ rccm.201704-0809OC.

21. Kessinger A, Wigton RS. Intracavitary bleomycin and tetracycline in the management of malignant pleural effusions: a randomized study. J Surg Oncol. 1987;36:81-3. 